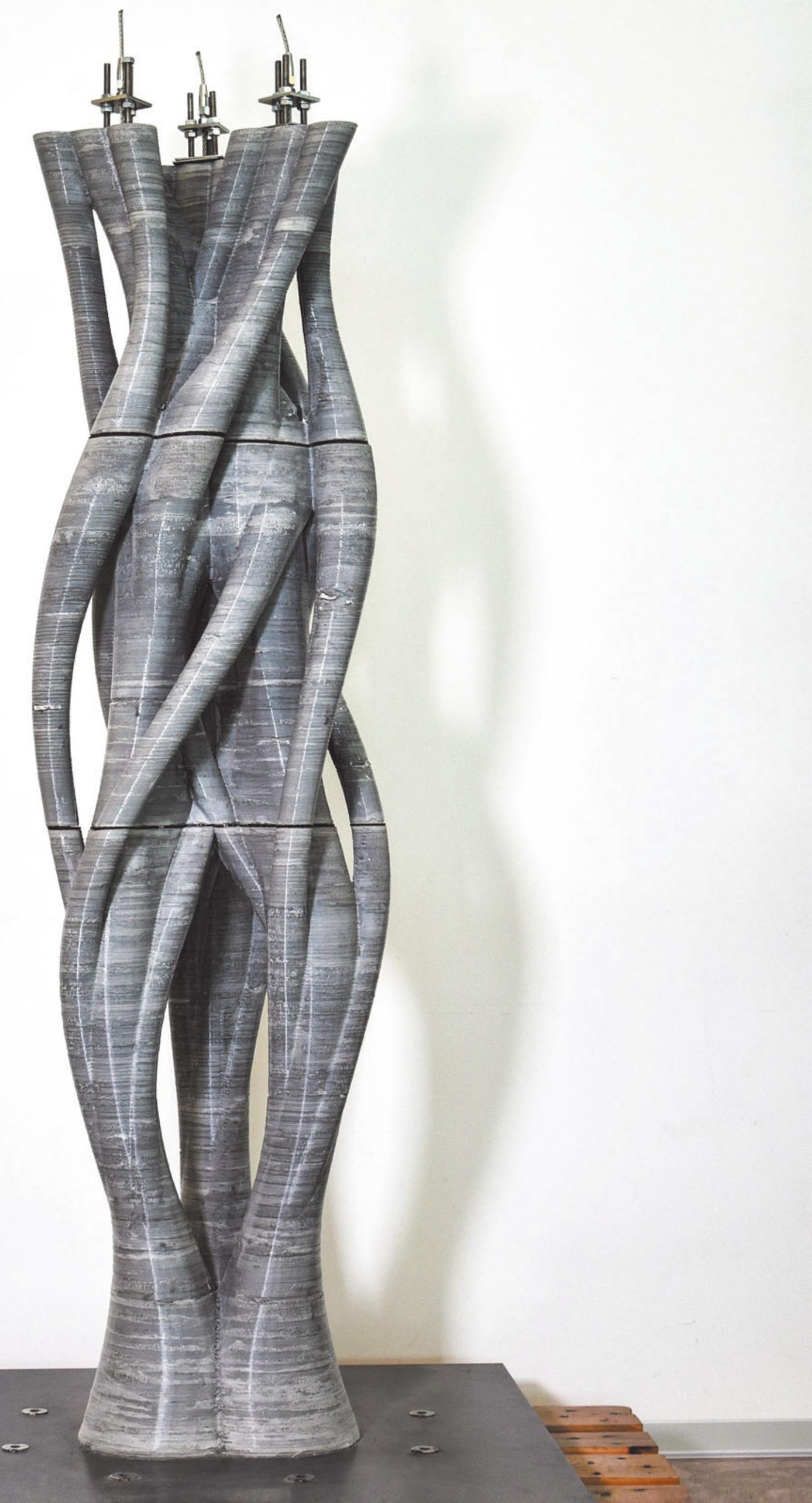




\title{
Eggshell: Ultra-Thin Three-Dimensional Printed Formwork for Concrete Structures
}

\author{
Joris Burger, ${ }^{1, *}$ Ena Lloret-Fritschi, ${ }^{1,2,{ }^{*}}$ Fabio Scotto, ${ }^{1,2}$ Thibault Demoulin, ${ }^{2}$ Lukas Gebhard, ${ }^{3}$ \\ Jaime Mata-Falcón, ${ }^{3}$ Fabio Gramazio, ${ }^{1}$ Matthias Kohler, ${ }^{1}$ and Robert J. Flatt ${ }^{2}$
}

\begin{abstract}
Concrete is a material favored by architects and builders alike due to its high structural strength and its ability to take almost any form. However, to shape concrete structures, heavy-duty formwork is usually necessary to support the fresh concrete while curing. To expand geometrical freedom, three-dimensional (3D) printed concrete formwork has emerged as a field of research. This article presents one possible application, a novel fabrication process that combines large-scale robotic fused deposition modeling 3D printing with simultaneous casting of a fast-hardening, set-on-demand concrete. This fabrication process, known as "Eggshell," enables the production of nonstandard concrete structures in a material-efficient process. By casting a fast-hardening concrete in a continuous process, lateral pressure exerted by the fresh concrete is kept to a minimum. In this way, a 1.5-mm-thin thermoplastic shell can be used as a formwork, without any additional support. Geometries of different scales are tested in this article to evaluate the feasibility of the Eggshell fabrication process in an architectural context. An array of printing materials are also tested, and several different reinforcement concepts are analyzed. The findings are used to produce a full-scale architectural demonstrator project. This article shows that a wide range of concrete geometries can be produced in a material-efficient fabrication process, paving the way toward mass customization and structural optimization within concrete architecture.
\end{abstract}

Keywords: 3D printing, formwork, robotic fabrication, set-on-demand concrete, digital concrete, architecture

\section{Introduction}

CONCRETE IS, BY far, the most used construction material in the world $^{1}$ and it has become practically impossible to imagine any building project without it. During construction, concrete needs to be supported by formwork as it transitions from a fluid material into a solid. Fabricating these formworks determines a large portion of the total construction costs of a concrete element, especially for nonstandard shapes (around $50 \%$ of costs for a standard element and up to $80-90 \%$ for a nonstandard element ${ }^{2}$ ). Therefore, although concrete can theoretically be shaped into almost any form, standard, orthogonal structures remain the norm, implying that structures are built with more material then truly needed.

Fused deposition modeling (FDM) three-dimensional (3D) printing of concrete formwork holds promise of enabling shape freedom in concrete architecture; however, so far the construction industry has been slow to adopt digital (fabrication) processes. ${ }^{3}$ Some of the reasons that FDM formwork

\footnotetext{
${ }^{1}$ Department of Architecture, Chair of Architecture and Digital Fabrication, ETH Zurich, Zurich, Switzerland.

${ }^{2}$ Department of Civil, Environmental and Geomatic Engineering, Physical Chemistry of Building Materials, Institute for Building Materials, ETH Zurich, Zurich, Switzerland.

${ }^{3}$ Department of Civil, Environmental and Geomatic Engineering, Institute of Structural Engineering, Concrete Structures and Bridge Design, ETH Zurich, Zurich, Switzerland.

*These authors contributed equally to this work.

(C) Joris Burger and Ena Lloret-Fritschi et al., 2020; Published by Mary Ann Liebert, Inc. This Open Access article is distributed under the terms of the Creative Commons License (http://creativecommons.org/licenses/by/4.0), which permits unrestricted use, distribution, and reproduction in any medium, provided the original work is properly cited.
}

Opposite page: Twisting Column - Design freedom in 3D printed Eggshell formwork. Master Thesis of Antonio Barney and Wenqian Yang, MAS DFAB, ETH Zürich. Photo Credits: Wenqian Yang. 
has not yet become widespread are the slow speed of the fabrication process, the typical small scale of prints, and the inability of the thin, fragile printed structures to hold the fresh concrete in place.

"Eggshell" addresses these issues as a novel fabrication method for nonstandard concrete structures. It uses a large-scale, robotic FDM process, combined with a set-on-demand digital concrete casting process developed within the project Smart Dynamic Casting (SDC). ${ }^{4}$ Eggshell seeks to enable the fabrication of bespoke, structural building elements in a nonwasteful process, while allowing for the integration of reinforcement.

\section{Relevant work}

Over the past decades, many processes have been developed to address the issues of formwork waste and shape freedom in concrete architecture. The most notable of these processes is $3 \mathrm{D}$ concrete printing (3DCP), first pioneered as a process called Contour Crafting. ${ }^{5}$ Currently, 3DCP is a subject of research at many research institutions and companies worldwide, and the first built examples are appearing. ${ }^{6-8}$ Although promising as a large-scale fabrication method due to generally high printing speeds, ${ }^{9}$ problems remain: particularly in cold joints between layers of printed concrete, ${ }^{10}$ and the difficulty of integrating reinforcement. ${ }^{11}$ For these reasons, many applications of 3DCP so far have been either nonloadbearing or as lost formworks. ${ }^{12}$

To extend fabrication freedom in formwork production, 3D printing has been further explored by several researchand industry projects. Spatial extrusion was used to create formwork by the Mesh Mould ${ }^{13}$ project as well as by Branch
Technologies. ${ }^{14}$ This method is promising, but these concrete structures still have to be manually finished in a postprocessing step. Another research project aims at using conventional FDM 3D printers to produce customized formwork parts that can be assembled, using sand or water to counter the lateral pressure from fresh concrete. ${ }^{15}$ This work has shown that highly complex parts can be successfully fabricated with a thin, lightweight formwork. ${ }^{16}$ However, the process is time-consuming and numerous smaller formwork pieces require assembly, leading to vulnerable joints between pieces.

Counter-pressure casting has also been used by Aectual, a company specializing in 3D printed building products, to create a staircase. ${ }^{17}$ An alternative approach to this method is to print a support structure around the formwork, as either a dissolvable ${ }^{18}$ or removable spatially extruded formwork. ${ }^{19}$ Although effective, printing these supports significantly increases printing time. In general, mitigating the high lateral pressure exerted on formwork remains a challenge for all projects involving FDM 3D printing, especially in elements of a larger size.

One project that has effectively addressed the challenge of controlling lateral pressure on a formwork is SDC. ${ }^{4}$ SDC is a robotically driven slipforming system for creating bespoke concrete structures, and a key aspect of the research is the invention of a digitally controlled set-on-demand material process. This allows concrete to enter the formwork in a fluid state and exit in a hardened state. By using a digital casting process and controlling hydration of the concrete, the material at the exit of the moving formwork is able to carry the load of the material above. ${ }^{20}$ A clear advantage of SDC process is that conventional reinforcement can be easily

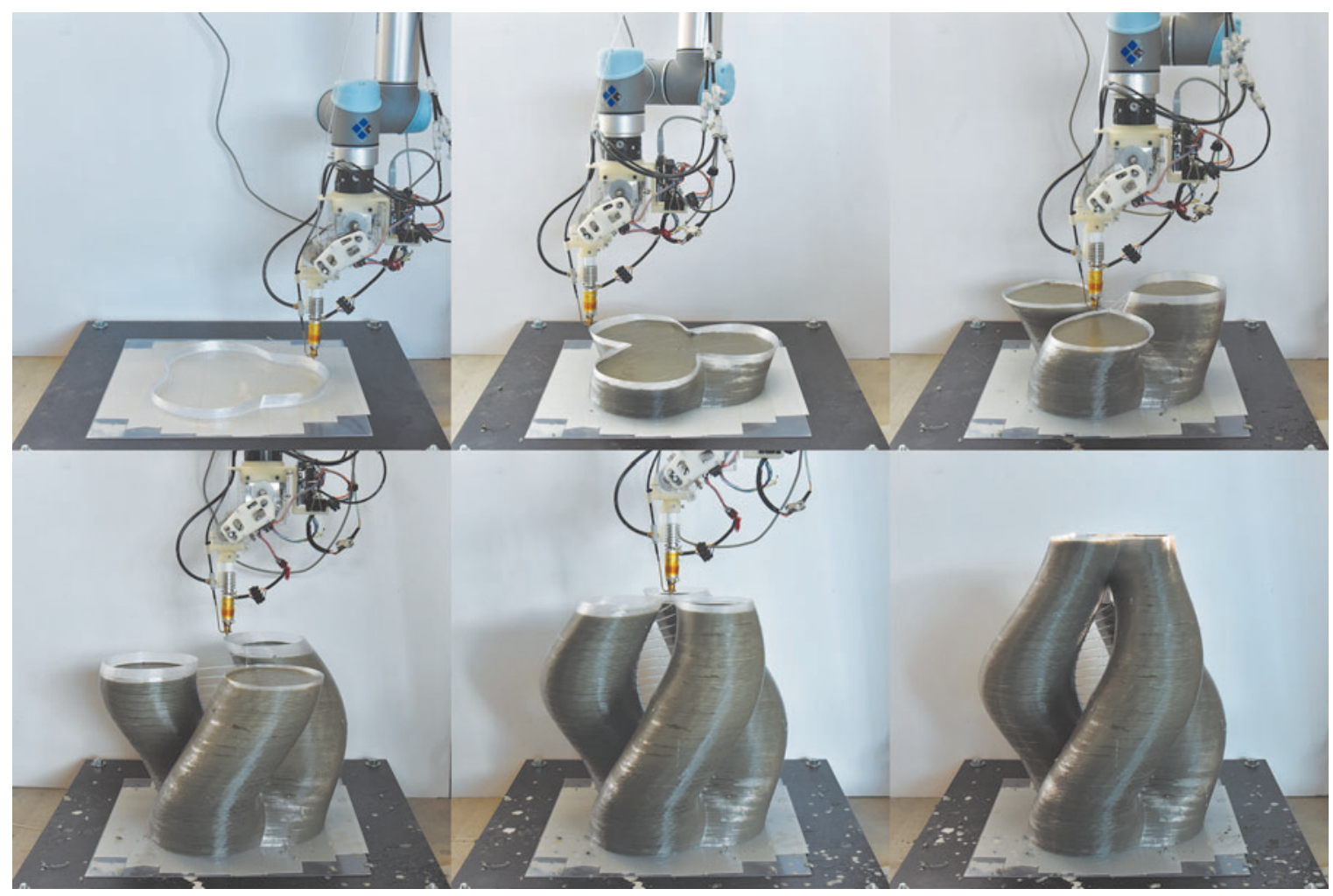

FIG. 1. Using the Eggshell fabrication process to produce a concrete column with three branches. Formwork material: polyethylene terephthalate glycol, layer height: $1.0 \mathrm{~mm}$ printing speed $25-45 \mathrm{~mm} / \mathrm{s}$, total fabrication time: $210 \mathrm{~min}$. 
introduced. Although SDC has extended the possibilities of digital fabrication with concrete, it is still limited in the range of geometries it can produce, due to complex mechanical actuation needed for the dynamic moving formwork.

\section{Eggshell}

The Eggshell concept ${ }^{21}$ was developed as a way to address the main limitations of SDC, while capitalizing on its advantages. As such, it merges large-scale robotic FDM 3D printing with the set-on-demand digital casting system developed within SDC. Other process exploiting such casting systems have been proposed and may generally be referred to as Digital Casting Technologies. ${ }^{22}$

In Eggshell, by exploiting the casting material chemistry and processing, it becomes possible to use a thin, singlelayered shell as formwork without any additional supports or counter-pressure material. Further, by printing the formwork, instead of actuating it as in SDC, a much wider range of geometries can be produced without losing the advantage of being able to include traditional reinforcement in structural building components.
The ultimate objective of Eggshell is to simultaneously print and fill a formwork (Fig. 1). This presents different advantages. First, it offers unrestricted access to the formwork to allow for precise casting and makes it easier to integrate reinforcement during fabrication. In addition, printing the formwork first may lead to a risk of buckling or damage of the formwork if it has to be moved. However, if the printing progresses as the formwork is filled with concrete, the hardening concrete effectively reduces the height to be considered for a risk of buckling.

\section{Scope of the study}

The original concept of Eggshell, simultaneous printing and filling, has been used to produce the Branching Column (Fig. 5) and the Twisting Column (Fig. 6) described in the Results section. Despite the advantages of using the Eggshell simultaneous fabrication process, it is also possible to print the formwork first and sequentially cast a set-on-demand concrete (consecutive fabrication process). This process has been used to produce the third demonstrator, the Future Tree (Fig. 8).

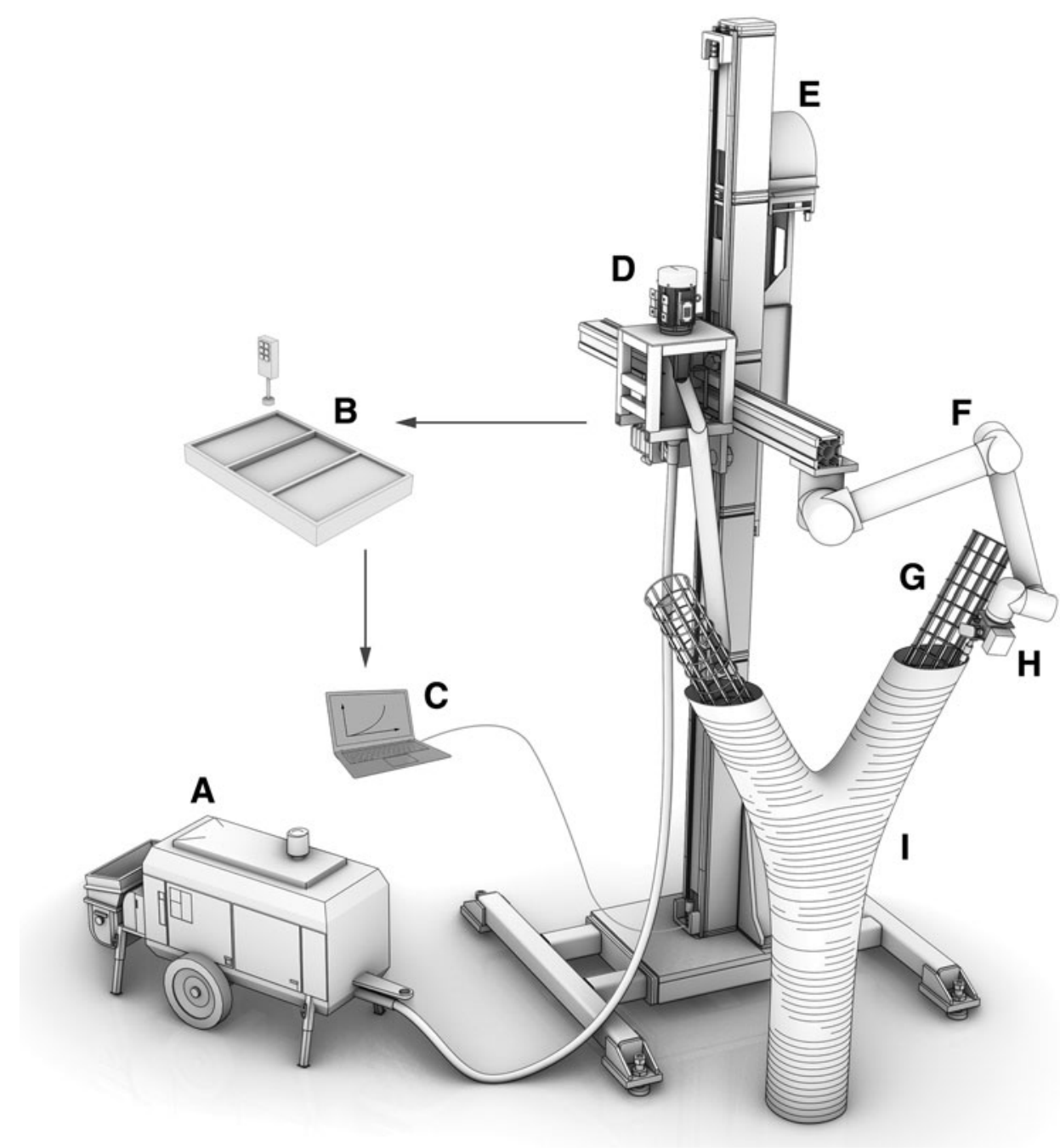

FIG. 2. Schematic representation of the Eggshell fabrication process. (A) Concrete pump. (B) Remote material feedback system. (C) Control system. (D) Inline mixer. (E) Vertical linear axis. (F) Six-axis robotic arm. (G) Reinforcement. (H) Extruder end-effector. (I) Three-dimensional printed formwork. 
Connected to the main target of Eggshell is the development of a simultaneous fabrication process where concrete is continuously filled in a digitally controlled process (in-line processing). This process has been used to fabricate the Branching Column; however, for both the Twisting Column and the Future Tree, an off-line concrete processing system has been used in which discrete batches of concrete were manually accelerated and cast. These small batches provide for a good representation of continuous processing, while making it easier to process material in a wide range of crosssections, as well as compensating for variations in material. From a materials chemistry point of view there is no significant change; however, increasing the robustness of continuous processing remains a topic of ongoing research. Reports on how deactivation and activation of concrete can be achieved are provided elsewhere. ${ }^{20,23}$

\section{Materials and Methods}

The different components of the fabrication setup are shown in Figure 2. They can be divided into three groups: control system (Fig. 2E, F), formwork printing system (Fig. 2H, I), and set-on-demand casting system (Fig. 2A-D). Fundamentally, the Eggshell process involves six steps: (1) designing the geometry, (2) generating the machine code, (3) preparing a batch of retarded concrete, (4) printing the formwork and simultaneous set-on-demand casting, (5) reinforcing, and (6) removal of the formwork and recycling. The setup, as well as the steps in the process are described next.

\section{Control system}

The moving parts of the setup consist of a six-axis robotic arm (Fig. 2F), mounted to a vertical linear axis (Fig. 2E). This setup offers a building volume of $1.2 \times 1.2 \times 3.6 \mathrm{~m}$. Despite the use of a robotic arm in this study, a three-axis gantry system would also be sufficient: In the studies presented, the six degrees of freedom offered by the robotic arm are not yet utilized. The robotic arm and axis are controlled through a custom-developed Python interface for the 3D modeling software Rhino 3D's ${ }^{24}$ plugin Grasshopper. $^{25}$

\section{Design}

To aid the design process, a computational tool has been developed in which the user directly generates the toolpaths that define the printed structure. In the tool a starting curve is created and then copied vertically to define the layers of the print. Vertical distance between the curves is defined as the layer height. The curves are then divided into points, with the distance between points defined as the resolution. The result of this can be interpreted as a 2D array of layers and points within the layers. Various transformations such as scaling, rotation, and translation can then be applied to the points to shape the geometry. Multiple contour curves can also be input to create geometries with multiple branches. This design tool offers a direct way to generate fabrication data, with precise control of the printed geometry. This helps to inform the design based on fabrication constraints, such as maximum overhang.

\section{Machine code}

The toolpath for the robotic arm and linear axis follows as a direct result of the points generated in the design step. Using a custom Python script, the commands are generated by transforming the points to coordinate planes and adding a printing speed and fillet radius, so that the robotic arm can smoothly transition between corners. The script exports the commands to a JSON file, which has commands for both the robotic arm and linear axis. The extruder code is generated through an Arduino ${ }^{26}$ script in which flow rate and nozzle temperature can be set.

\section{Formwork printing}

Attached to the robotic arm is an extruder end-effector (Fig. 2H) used for 3D printing the formwork (Fig. 2I). The tool is a self-built filament extruder with a nozzle diameter of $1.5 \mathrm{~mm}$. It uses a standard 2.85-mm filament, has a maximum flow rate of $0.25-0.35 \mathrm{~kg} / \mathrm{h}$ and a maximum nozzle temperature of $270^{\circ} \mathrm{C}$. The extruder motor and heating elements are controlled through the previously mentioned Arduino ${ }^{26}$ script.

As a measure of the speed at which structures can be built, vertical printing rate (VPR) is introduced as a parameter. Concrete is always cast in a vertical process and, therefore, the vertical speed is relevant. The VPR is defined as the height of a structure that can be printed within a given time. As the 3D printed formworks consist only of an outer curve without infill (structures commonly referred to as "vases",27 within the 3D printing community), the VPR at a predefined cross-section of a structure is given by the following formula:

$$
\begin{aligned}
& \text { vertical printing rate }(\mathrm{mm} / \mathrm{min})= \\
& \frac{\text { layer height }(\mathrm{mm}) \cdot \operatorname{printing} \text { speed }(\mathrm{mm} / \mathrm{s})}{\text { perimeter }(\mathrm{mm})} \times 60
\end{aligned}
$$

Typically, layer height and printing speed are kept constant during the fabrication process. Depending on the geometry of the printed structure, the perimeter typically varies over the height, meaning that the VPR varies with it.

To start the printing process, the JSON file generated in the previous step is executed on a computer connected to the vertical linear axis and robotic arm. In case of a simultaneous process (such as in the first and second demonstrators), the formwork is then filled with accelerated concrete while it is being printed.

\section{Set-on-demand casting system}

The set-on-demand casting system used by the Eggshell process has been adopted from the SDC project. ${ }^{4}$ Three different mix designs were used throughout this article, and they are provided in Supplementary Table S1. The general principle is that a large batch of retarded concrete is mixed, ensuring its workability for up to $8 \mathrm{~h}$. Then, incremental volumes of the retarded concrete are taken and activated by adding small amounts of accelerator (dosage and source provided in Supplementary Table S1). As mentioned earlier, this has been done in a method of in-line, digital processing for the first demonstrator and in an off-line, manual method for the second and third demonstrators.

\section{Reinforcement}

As concrete is strong in compression but weak and brittle in tension, reinforcement is necessary to resist tensile forces and to produce load-bearing, code-compliant concrete 
elements. Eggshell presents a wide range of possibilities, in which the reinforcement can be:

(I) Arranged before the concrete production (either before, during, or after printing the shell formwork) (Fig. 3A),

(II) Added to the concrete matrix itself (e.g., using short pumpable fibers),

(III) Placed in between casting layers (e.g., using hooked fibers) (Fig. 3B), or

(IV) Post-installed in prefabricated ducts (e.g., using post-tensioning reinforcement) (Fig. 3B).

The first approach is the closest to standard reinforced concrete solutions found on most construction sites. This allows the use of conventional reinforcement and design methods, but it might limit geometric freedom as the reinforcement cannot be precisely prefabricated to fit very complex geometries. ${ }^{28}$ Further, for this to be used in a simultaneous fabrication process, the robotic arm would have to move around the preplaced reinforcement (Fig. 3A), adding complexity in robotic path planning.

The use of fibers in the fabrication process [approaches (II) and (III)] expands the design space to more complex geometries. However, mixing fibers into the concrete matrix (II) complicates concrete processing and requires short, expensive fibers. These issues might be overcome by splitting the continuous casting process into several steps and placing fibers in between these casting steps (III), which additionally allows for aligning and grading the fibers according to structural needs (Gebhard, L., Mata-Falcón, J., Markić, T. and Kaufmann W. "Aligned interlayer fibre reinforcement for digital fabrication with concrete," in RILEM-fib X International Symposium on Fibre Reinforced Concrete, BEFIB2020, Valencia, 2020. Abstract submitted).

Since fibers do not provide sufficient strength and ductility by themselves, they should be complemented with additional post-installed reinforcement [approach (IV)]. Post-tensioning reinforcement can be easily implemented by using empty ducts left during the Eggshell production. These ducts also allow casting a strain-hardening fiber-reinforced material (e.g., Ultra-High-Performance Fiber-Reinforced Concrete) into them, which is an alternative to post-install reinforcement that is well suited for elements with highly complex geometries. The ideal reinforcing solution for a certain application will involve one or several of the presented reinforcing approaches depending, among other factors, on the complexity of the geometry.

\section{Removal of the formwork}

Although the concrete material is self-supporting within 1$2 \mathrm{~h}$, leaving the formwork in place for a longer period results in better curing conditions. After 1-3 days, the formwork can be removed by using a heat gun and pliers. Any traces of concrete must then be washed off before the material can be recycled. Although recycling of the formwork is theoretically possible, this has not yet been experimentally verified.

\section{Results and Discussion}

Eggshell aims at innovating the production of full-scale, architectural elements. Initial studies were aimed at establishing fabrication parameters. Subsequently, concrete structures in different scales were fabricated, concluding with a structure implemented in an architectural context.

\section{Process development}

Vertical printing rate. A first study was aimed at selecting a material and tool that would have optimal results for the process. Different combinations of layer height and printing speed were tested together with different materials, to achieve the highest VPR with good print quality. Three materials were tested: polylactic acid (PLA), polypropylene (PP), and polyethylene terephthalate glycol (PET-G). PLA was printed by using a Flexion Extruder ${ }^{29}$ desktop 3D printer at high printing speed $(40-80 \mathrm{~mm} / \mathrm{s})$ and low layer height $(0.3-0.5 \mathrm{~mm})$; PP was printed at low printing speed (6$10 \mathrm{~mm} / \mathrm{s})$ but high layer height $(5-7 \mathrm{~mm})$ by using a BAK Dohle ExOn 3A industrial plastic welder. ${ }^{30}$ PET-G was printed at an average printing speed $(30-50 \mathrm{~mm} / \mathrm{s})$ and an average layer height $(0.8-1.2 \mathrm{~mm})$, by using the self-built filament extruder. The results are presented in Table 1.

The experiments using PP gave the highest VPR, as they used an industrial plastic welding machine with a 5-mmdiameter filament and a $10-\mathrm{mm}$ nozzle. However, as this
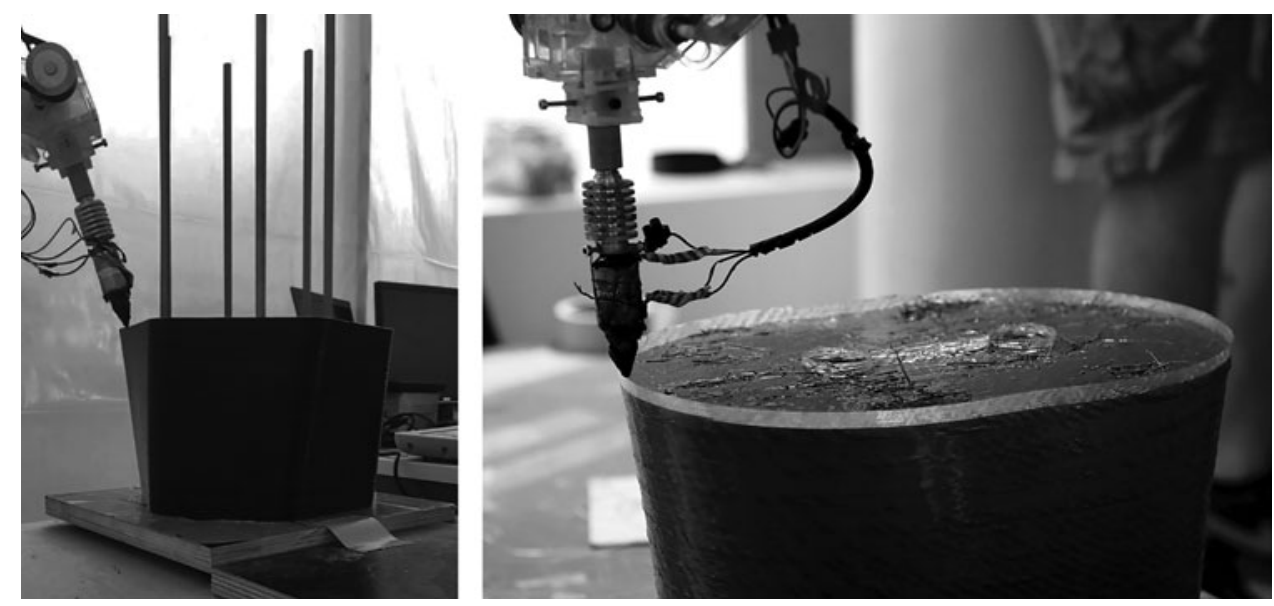

FIG. 3. Left: printing around preplaced reinforcement. Right: placing fibers in between casting layers and integrating posttensioning ducts. 
Table 1. Maximum Vertical Printing Rate That Could Be Obtained with Different Materials and Tools, Assuming a Constant Perimeter of 1000 mm (Straight Column of $250 \times 250$ mm)

\begin{tabular}{|c|c|c|c|c|c|c|}
\hline Material & Extrusion tool & $\begin{array}{l}\text { Nozzle } \\
\text { diameter } \\
(\mathrm{mm})\end{array}$ & $\begin{array}{l}\text { Filament } \\
\text { diameter } \\
(\mathrm{mm})\end{array}$ & $\begin{array}{l}\text { Printing } \\
\text { speed } \\
(\mathrm{mm} / \mathrm{s})\end{array}$ & $\begin{array}{l}\text { Layer } \\
\text { height } \\
(\mathrm{mm})\end{array}$ & $\begin{array}{c}\text { Maximum vertical } \\
\text { printing rate } \\
(\mathrm{mm} / \mathrm{min})\end{array}$ \\
\hline Polylactic acid & Flexion Extruder ${ }^{31}$ & 0.6 & 1.75 & $40-80$ & $0.3-0.5$ & 2.4 \\
\hline Polypropylene & BAK Dohle ExOn $3 \mathrm{~A}^{32}$ & 10.0 & 5 & $6-10$ & $5-7$ & 4.2 \\
\hline $\begin{array}{l}\text { Polyethylene } \\
\text { terephthalate glycol }\end{array}$ & Self-built filament extruder & 1.5 & 2.85 & $30-50$ & $0.8-1.2$ & 3 \\
\hline
\end{tabular}

extruder nozzle diameter was large, material usage was extremely high. It also resulted in a relatively thick $(10 \mathrm{~mm})$ wall, which is more difficult to remove and less aligned with the concept of a thin shell. The tests using PLA resulted in the lowest VPR. The best results were achieved with PET-G and the self-built filament extruder previously described, by using a layer height of around $1.0 \mathrm{~mm}$ and a printing speed of around $50 \mathrm{~mm} / \mathrm{s}$. PET-G generally offers better chemical resistance than other common $3 \mathrm{D}$ printing thermoplastics and is, therefore, better suited for use in combination with concrete. ${ }^{31}$ All further tests were, therefore, conducted by using PET-G.

Controlling thermoplastic layer-to-layer bonding. A critical aspect for successfully filling such formworks with concrete is avoiding delaminations and weaknesses between the FDM printed layers. Issues with delamination were encountered for larger prints, in particular for the Future Tree. This is best explained by shrinkage of the material: As an extruded layer of filament cools more from the top, it contracts, causing the edges to warp upward. The problem is complex due to heat conduction between the printed layers; however, examining the details of the underlying physics goes beyond the scope of this article. Instead, a pragmatic solution is proposed, allowing Eggshell to be used for largescale fabrication.

The problem of delamination scales with the size of the print, so larger prints have larger absolute deformations. ${ }^{32}$ Further, as the filament shrinks mostly in the longitudinal direction of the layer path, the warping effect can concentrate in corners. ${ }^{33}$ To study this behavior, various geometries with a diameter of $1 \mathrm{~m}$ were printed by using a
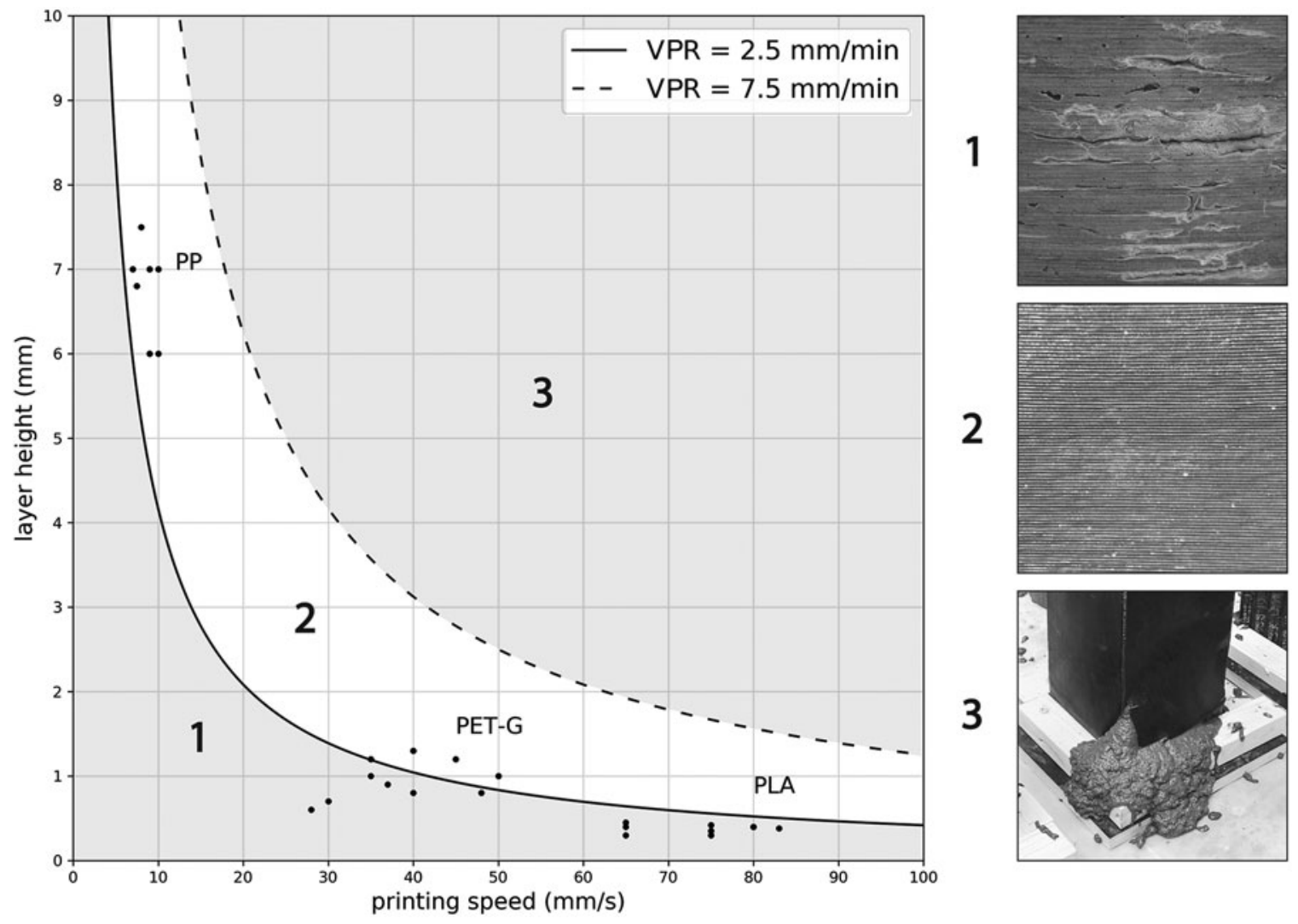

FIG. 4. Printing speed plotted against layer height. The continuous line shows a VPR of $2.5 \mathrm{~mm} / \mathrm{min}$, and the discontinuous line shows a VPR of $7.5 \mathrm{~mm}$ for a straight column with a constant perimeter of $1000 \mathrm{~mm}$. Area 1 indicates a VPR of $0<2.5 \mathrm{~mm} / \mathrm{min}$, resulting in cold joints between layers, area 2 indicates a VPR of $2.5<7.5 \mathrm{~mm} / \mathrm{min}$, resulting in a satisfactory surface quality, and area 3 indicates a VPR of $>7.5 \mathrm{~mm} / \mathrm{min}$, resulting in breakage of the formwork. The three groups of data points indicate the parameters of the experiments on VPR from the first section in this chapter. VPR, vertical printing rate. 

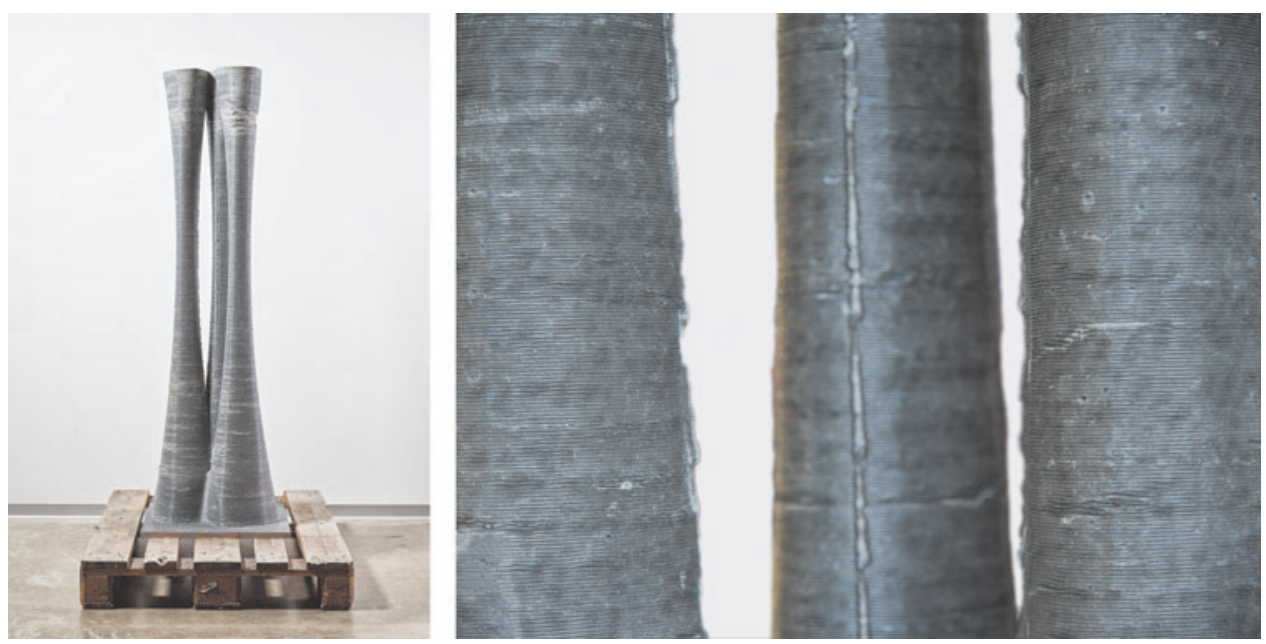

FIG. 5. One thousand six-hundred-millimeter-tall early prototype, printed in $450 \mathrm{~min}$ with a layer height of $1.2 \mathrm{~mm}$, printing speed of $45 \mathrm{~mm} / \mathrm{s}$, and average VPR of $3.55 \mathrm{~mm} / \mathrm{min}$.

layer height of $1.0 \mathrm{~mm}$ and a printing speed of $45 \mathrm{~mm} / \mathrm{s}$. Tested geometries included a circle (Fig. 7A), regular polygons (Fig. 7B), star polygons (Fig. 7D, E), polygons with filleted edges (Fig. 7C), n-gon (Fig. 7G-I), and a section of the Future Tree column design (Fig. 7F).

It was found that, by applying a zigzag or chevron pattern to the geometry, detrimental shrinkage could be avoided
(Fig. 7G-I). As the straight sections in these geometries are short, forces acting on the corners due to shrinkage are low. This pattern may also result in a higher flexibility in the structure (allowing minor deformations before delaminating), although the final printed shape did not show substantial difference with the planned printing path. Higher resolution measurements will be necessary in the future to give more
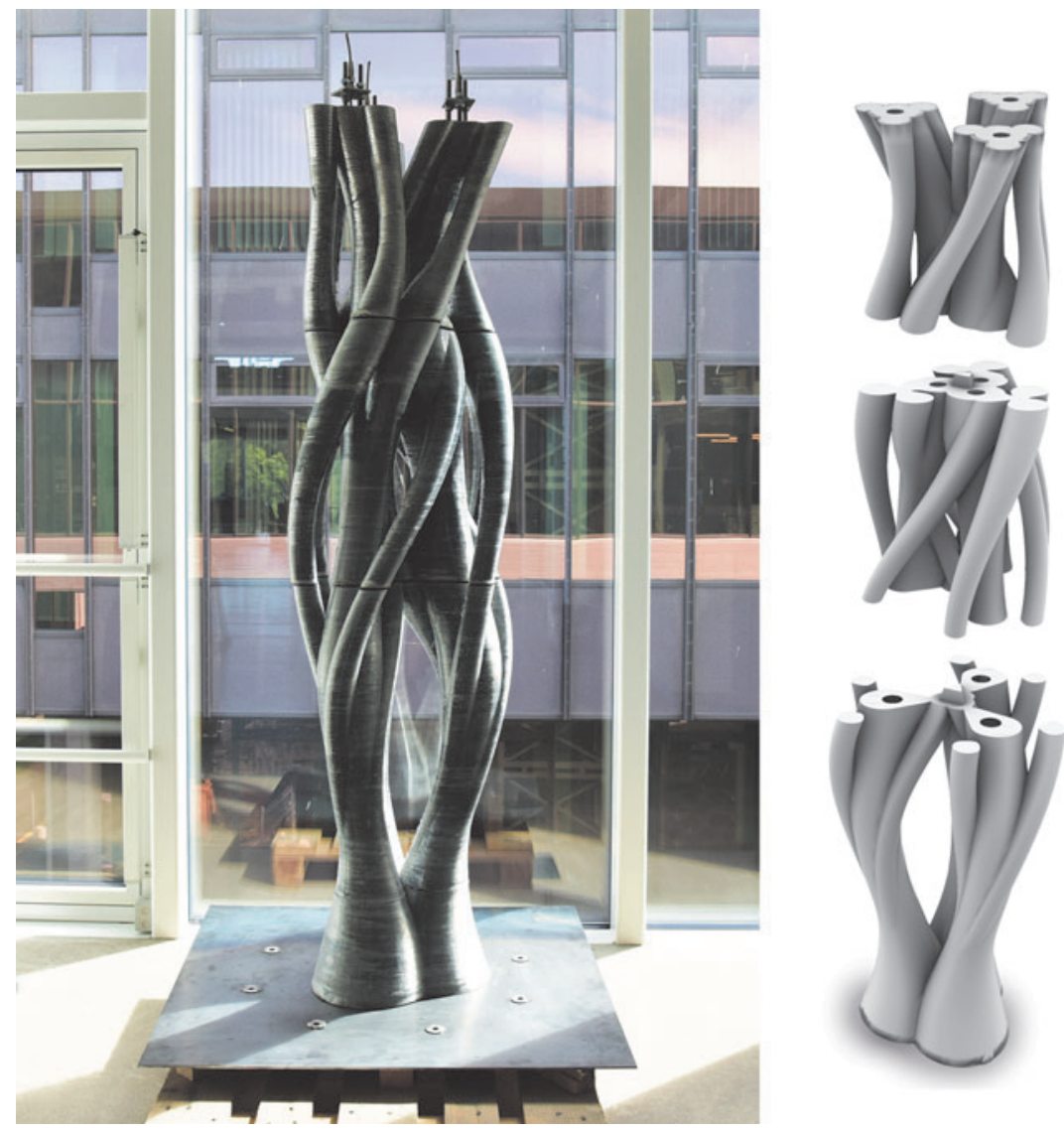

FIG. 6. Left: $1800 \mathrm{~mm}$ tall Branching Column fabricated in three parts by using a simultaneous process. Layer height: $1 \mathrm{~mm}$, printing speed: $30-50 \mathrm{~mm} / \mathrm{s}$, fabrication time of parts (bottom to top): $12,10,7 \mathrm{~h}$. Right: Void spaces are printed inside the three main branches so that cables can be inserted post-fabrication to tension the elements together. Design and fabrication: A. Barney and W. Yang. 

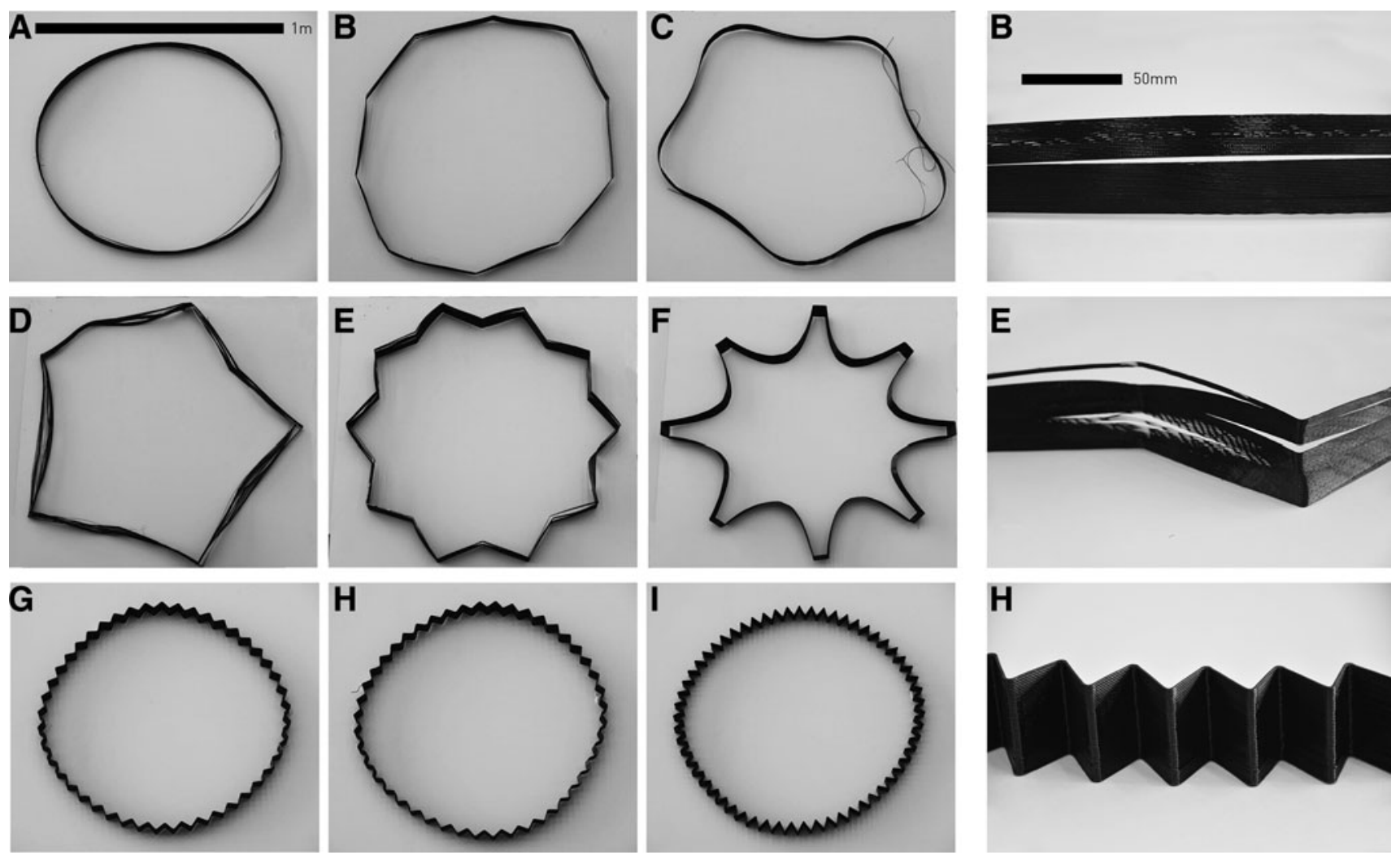

FIG. 7. Left: different printing tests with a diameter of $1 \mathrm{~m}$, printed with a layer height of $1 \mathrm{~mm}$ and printing speed of $50 \mathrm{~mm} / \mathrm{s}$. Right: close-up of printed layers.

attention to this problem. Further, the printing speed in corners is not changing substantially, so this should not be considered as denser zones offering "anchor points."

These results indicate that the maximum length of a straight edge should not exceed $70 \mathrm{~mm}$, to print the formwork without layer delamination. This was used as an input to generate the final design of the Future Tree. For the other two structures, having smaller dimensions, this was not necessary.

Overhang. To define the geometric possibilities of the Eggshell process, a set of experiments were conducted to determine the maximum possible overhang. Four models with a height of $300 \mathrm{~mm}$ and overhang angles ranging from $15^{\circ}$ to $45^{\circ}$ were printed in PET-G, using a constant printing speed of $45 \mathrm{~mm} / \mathrm{s}$ and a layer height of $1.2 \mathrm{~mm}$. They were then filled with a set-on-demand concrete in $100 \mathrm{~min}(3 \mathrm{~mm} /$ min). These tests showed that an overhang of $35^{\circ}$ could be successfully filled. However, breakage occurred in the $45^{\circ}$ model after filling to $100 \mathrm{~mm}$ in height. ${ }^{34}$

A later study showed that it was also possible to print and fill volumes of a smaller diameter with an overhang of $65^{\circ}$ by changing the printing speed based on the angle between layers. ${ }^{35}$ In case of a larger overhang, one can print more slowly
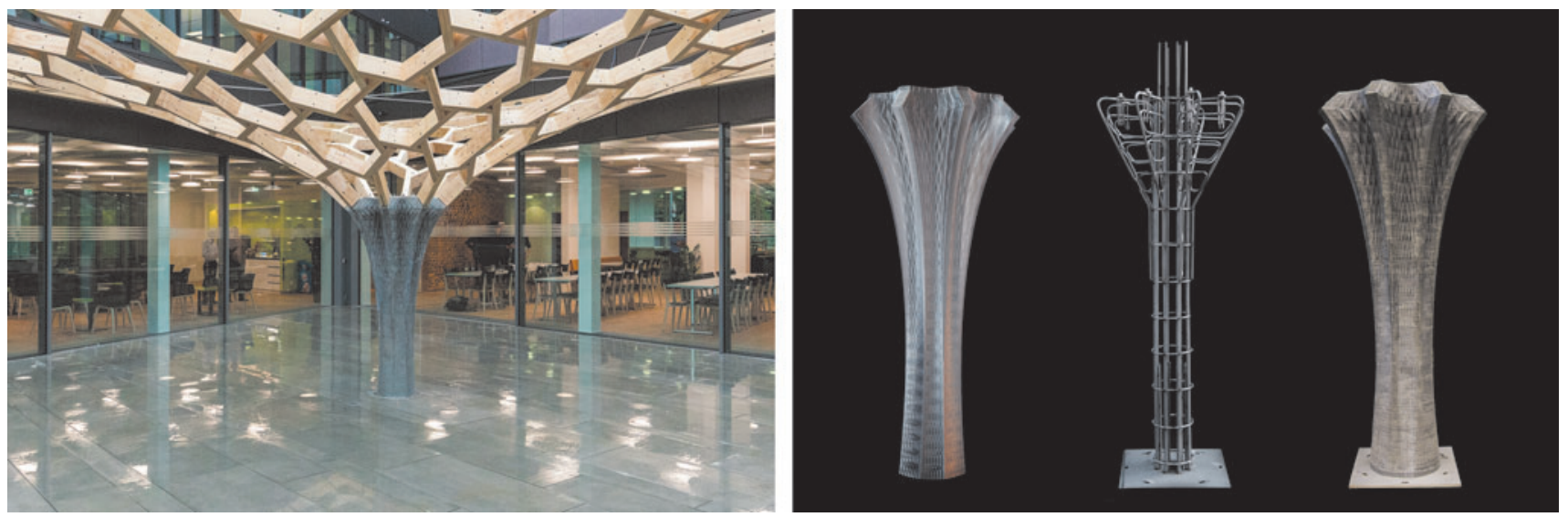

FIG. 8. Left: completed Future Tree pavilion (Image: Basler \& Hofmann AG, Stefan Kubli). Right: printed formwork, reinforcement cage, and finished concrete element. 
while keeping the flow rate constant to deposit more material in one place and create a stronger bond between layers. Thus, using a printing speed ranging from 20 to $40 \mathrm{~mm} / \mathrm{s}$, structures with a wide range of overhangs can be printed.

Filling rate. The minimum and maximum concrete filling rates to avoid cold joints and formwork breakage were established. Due to printing speed limitations it was impossible to reach a VPR higher than $4.2 \mathrm{~mm} / \mathrm{min}$, so geometries were preprinted and then filled with concrete (setting time of $60 \mathrm{~min}$ ) at different filling rates. Figure 4 shows the results of this study, illustrating how a low VPR $(<2.5 \mathrm{~mm} / \mathrm{min})$ results in cold joints in the concrete, whereas a high VPR $(>7.5 \mathrm{~mm} /$ $\min )$ results in breakage of the formwork. This means that VPR and concrete filling rate should be kept in between 2.5 and $7.5 \mathrm{~mm} / \mathrm{min}$ for concrete with a setting time of $60 \mathrm{~min}$. This also illustrates how a high VPR can only be successfully achieved with concrete with a faster setting time. Recent developments have already led to material mixes with a faster setting time; however, these are not described in this article.

The rate at which concrete is placed should be analyzed in terms of rate of rise, analogous to the VPR and related to the rate at which the material should harden. However, from a processing point of view, we have to consider the crosssection area, which multiplied by the vertical filling speed gives a volumetric filling rate. Since concrete pumps have limited flexibility in the volumetric flow ranges, this puts a limit onto the range of cross-sections that can be produced with a certain device.

As both the Twisting Column and the Future Tree had large variations in cross-section, the off-line, manual filling process was used to fill these structures. In this process, discrete volumes of concrete are mixed and placed manually in the formwork. The volumes of these mixes are adjusted in relation to the cross-sectional area, so that each of the added layers does not lead to an excess pressure that could damage the formwork. The added volumes should also be limited to reduce the time between additions and avoid cold joints being produced such as in 3DCP. ${ }^{10,36}$ For Eggshell, however, the risk is much lower as the subsequent concrete layers are not as stiff. The problem is further reduced if in-line, continuous filling can be applied.

\section{Demonstrators}

Branching Column. After parameter calibration, studies were aimed at providing a proof of concept for the method. A 1600-mm-tall prototype (Fig. 5) was printed and filled in $450 \mathrm{~min}$, giving an average VPR of $3.55 \mathrm{~mm} / \mathrm{min}$ with a layer height of $1.2 \mathrm{~mm}$ and printing speed of $45 \mathrm{~mm} / \mathrm{s}$. Simultaneously, concrete was cast every $5 \mathrm{~min}$ in layers ranging from 10 to $30 \mathrm{~mm}$. The in-line material processing system was used; however, concrete was manually cast into the formwork. As the VPR was higher than $2.5 \mathrm{~mm} / \mathrm{min}$, no cold joints could be seen between layers.

Twisting Column. The aim of the second demonstrator was to demonstrate the possibility of simultaneous fabrication to produce complex geometries. Moreover, as designs for structurally optimized geometry often feature multiple branches (multiple contours per layer), several models with a branching typology were fabricated. Such geometries inherently call for alternative reinforcement solutions and, thus, the applicability of post-tensioning was tested.
In the development process of this demonstrator, models with three branches (Fig. 1) and five branches were fabricated. The final structure with up to 12 individual branches (Fig. 6) was printed in three separate elements that were then assembled with post-tensioning. This opens up interesting perspectives for Eggshell, allowing geometries to be fabricated that are clearly difficult to produce otherwise, at least in an efficient way. These designs were not structurally optimized, but they show the geometrical possibilities of the process.

Future Tree. To show the possibilities of large-scale fabrication, a concrete column was chosen as an architectural demonstrator project. The column is part of the Future Tree pavilion commissioned by Swiss engineering firm Basler \& Hofmann. ${ }^{37}$ For this project a concrete column was prefabricated with a height of $2.1 \mathrm{~m}$ and top and bottom diameters of 1 and $0.4 \mathrm{~m}$, respectively. The main challenges that had to be addressed were the integration of reinforcement, shrinkage of the 3D printed filament at large scales, difficulty of resisting lateral pressure of the concrete due to the lower surface to volume ratio, and tolerance of connection details (Burger, J., Lloret-Fritschi, E., Taha, N., Scotto, F., Demoulin, T., Mata-Falcón, J., Gramazio, F., Kohler, M. and Flatt, R. J. "Eggshell: Design and Fabrication of a NonStandard, Structural Concrete Column Using Ultra-Thin, 3DPrinted Formwork." in Digital Concrete 2020, Eindhoven. Abstract accepted).

For a formwork of this size, layer delamination during printing presented a major challenge. Solutions for this issue are discussed in the Section: "Controlling layer to layer bonding and avoiding delamination." The final column formwork was continuously printed over a period of $26 \mathrm{~h}$ with a layer height of $1.0 \mathrm{~mm}$ and printing speed of $45 \mathrm{~mm} / \mathrm{s}$, resulting in an average VPR of $1.34 \mathrm{~mm} / \mathrm{min}$. As the VPR was too low to be cast and printed simultaneously, this was done by using the consecutive process.

After printing the formwork, the prefabricated reinforcement cage was placed inside and the formwork was filled with concrete in $8 \mathrm{~h}$, resulting in an average concrete filling rate of $4.3 \mathrm{~mm} / \mathrm{min}$. This clearly illustrates the discrepancy between speed of 3D printing and concrete filling. To be able to fill this structure simultaneously, the VPR needs to increase by at least a factor of 2 . Nevertheless, the Future Tree column demonstrates a first architectural application of the Eggshell consecutive process: using a thin 3D printed formwork with set-on-demand concrete casting.

\section{Conclusions and Next Steps}

This work presents a novel fabrication process that aims at realizing nonstandard concrete structures in an effective and sustainable way. Although the research is still in its early stages, it has shown that objects of a scale relevant to architecture can be fabricated. The Eggshell simultaneous fabrication process shows potential for making a wide range of geometries possible, but its success will depend on whether printing can be sped up. Achieving a faster vertical formwork printing rate is necessary to fabricate objects of a larger scale without causing cold joints. There are, however, several possibilities of increasing speed, by making use of either large, high-output extruders $^{38,39}$ or state-of-the-art extrusion techniques. ${ }^{40}$ 
Using formwork prefabrication and set-on-demand concrete casting, it is already feasible to produce full-scale elements. However, there are limits on the geometrical potential of this consecutive fabrication method, as complex geometries may not allow the concrete to flow and self-compact well in the formwork. Also, fitting a prefabricated reinforcement cage within a printed formwork can restrict the geometry of the formwork. Indeed, the issue of reinforcement in digital fabrication with concrete requires broader attention. Concepts presented here offer complementary solutions to already existing ones. ${ }^{41,42}$

To achieve the most sustainable process possible, we are improving the recyclability of used formworks, and examining alternative printing materials. To make the process economically viable and less labor intensive, research efforts should also be directed toward a fully automated concrete casting process, eliminating the need for human intervention. As research progresses and the process is stabilized and streamlined, the range of building components produced could extend to beams, floor slabs, or connecting and transitional elements, paving the way toward sustainable mass customization in concrete architecture.

\section{Acknowledgments}

The authors thank Tobias Ulrich and Martin Wermelinger for the successful collaboration resulting in a patent for the Eggshell concept, as well as Antonio Barney and Wenqian Yang for their master thesis as part of the MAS Digital Fabrication. Timothy Wangler and Lex Reiter are thanked for their input and fruitful discussions. Lastly, Heinz Richner, Andreas Reusser, Michael Lyrenmann, and Philippe Fleischmann are acknowledged for their technical support.

\section{Author Disclosure Statement}

The Eggshell concept was filed as a European Patent Application under patent no. WO 2019/121316 A1. ${ }^{21}$

\section{Funding Information}

This research was supported by the NCCR Digital Fabrication, funded by the Swiss National Science Foundation (NCCR Digital Fabrication Agreement no. 51NF40-141853).

\section{Supplementary Material}

Supplementary Table S1

\section{References}

1. Crow JM. The concrete conundrum. Chem World 2008:6266.

2. Schipper HR, Grünewald S. Efficient material use through smart flexible formwork method. In: ECO-Crete Int. Symp. Environ. Friendly Concr. Iceland: Reykjavik, 2014; pp. 1-8.

3. McKinsey \& Company. Imagining Construction's Digital Future, 2016.

4. Lloret E, Shahab AR, Linus M, et al. Complex concrete structures: Merging existing techniques with digital fabrication. Comput-Aided Des 2015;60:40-49.

5. Khoshnevis B, Hwang D, Yao K.-T, et al. Mega-scale fabrication by contour crafting. Int J Ind Syst Eng 2006;1: 301-320.
6. Wangler T, Roussel N, Bos FP, et al. Digital concrete: A review. Cem Concr Res 2019;123:105780.

7. Salet TAM, Ahmed ZY, Bos FP, et al. Design of a 3D printed concrete bridge by testing. Virtual Phys Prototyp 2018;13:222-236.

8. Apis Cor collaborates on world's largest 3D printed building. 3Dnatives, 2019. https://www.3dnatives.com/en/ apis-cor-largest-3d-printed-building-261020194/ Accessed November 12, 2019.

9. Anton A, Yoo A, Bedarf P, et al. Vertical modulations: Computational design for concrete 3D printed columns. In: Ubiquity Auton.-Proc. ACADIA Conf. The University of Texas at Austin, Austin, Texas, 2019; pp. 596-605.

10. Wangler $\mathrm{T}$, Lloret $\mathrm{E}$, Reiter $\mathrm{L}$, et al. Digital concrete: Opportunities and challenges. RILEM Tech Lett 2016; 1:67-67.

11. Asprone D, Menna C, Bos FP, et al. Rethinking reinforcement for digital fabrication with concrete. Cem Concr Res 2018;112:111-121.

12. XtreeE The large-scale 3d, Post in Aix-en-provence, 2017. www.xtreee.eu/post-in-aix-en-provence/ Accessed December $1,2019$.

13. Hack N. Mesh Mould: A robotically fabricated structural stay-in-place formwork system, PhD Thesis. ETH Zurich, 2018.

14. Branch Technologies (n.d.). https://www.branch.technology/ Accessed December 10, 2019.

15. Jipa A, Bernhard M, Dillenburger B. Submillimeter formwork. 3D-printed plastic formwork for concrete elements. In: TxA Emerg. Des. Technol. Conf., Austin, Texas, USA, 2017.

16. Jipa A, Bernhard M, Ruffray N, et al. Formwork fabrication freedom for a concrete canoe. Gest Tecnol Proj 2019;14: $25-44$.

17. Aectual. Aectual Stair (n.d.). https://www.aectual.com/ stair/ Accessed December 10, 2019.

18. Leschok M, Dillenburger B. Dissolvable 3DP formwork. In: Ubiquity Auton.-Proc. ACADIA Conf. Austin, Texas: The University of Texas at Austin, 2019.

19. AI Build. AI build: Concrete formwork (2017). https://aibuild.com/concreteformwork.html Accessed December 10, 2019.

20. Reiter L, Wangler T, Roussel N, et al. The role of early age structural build-up in digital fabrication with concrete. Cem Concr Res 2018;112:86-95.

21. Gramazio F, Kohler M, Flatt R, et al. Method of vertical forming of a concrete wall structure and apparatus therefore, European Patent: WO 2019/121316 A1, 2019.

22. Lloret-Fritschi E, Wangler T, Gebhard L, et al. From smart dynamic casting to a growing family of digital casting systems. Cem Concr Res 2020; In press.

23. Marchon D, Kawashima S, Bessaies-Bey H, et al. Hydration and rheology control of concrete for digital fabrication: Potential admixtures and cement chemistry. Cem Concr Res 2018;112:96-110.

24. Robert McNeel \& Associates. Rhinoceros (n.d.). https:// www.rhino3d.com/ Accessed December 9, 2019.

25. David Rutten. Grasshopper 3D (n.d.). https://www .grasshopper3d.com/ Accessed September 12, 2019.

26. Arduino (n.d.). https://www.arduino.cc Accessed November 12, 2019.

27. Gharge P. Cura vase mode: The basics-simply explained, 2019. https://all3dp.com/2/cura-vase-mode-all-you-needto-know/ Accessed December 12, 2019. 
28. Lloret-Fritschi E, Scotto F, Gramazio F, et al. Challenges of real-scale production with smart dynamic casting. In: Wangler T, Flatt RJ (eds). First RILEM Int. Conf. Concr. Digit. Fabr.-Digit. Concr. 2018. Springer International Publishing, 2019; pp. 299-310.

29. Flexion Extruder (n.d.). https://flexionextruder.com/ Accessed November 29, 2019.

30. Bak Dohle (n.d.). https://www.bak-ag.com/products/category/ hand-welding-extruders Accessed November 29, 2019.

31. Filaments Directory. PETG filaments for your 3D printer (n.d.). https://www.filaments.directory/en/plastics/petg Accessed December 1, 2019.

32. Wijnen B, Sanders P, Pearce JM. Improved model and experimental validation of deformation in fused filament fabrication of poly lactic acid. Prog Addit Manuf 2018;3:1-23.

33. Alsoufi MS, Elsayed AE. Warping deformation of desktop 3D printed parts manufactured by open source fused deposition modeling (FDM) system. Int $\mathrm{J}$ Mech Mechatron Eng 2017;17:11.

34. Burger J. Eggshell: Design and fabrication of non-standard, structural concrete columns, using 3D printed thin-shell formwork, Master Thesis. TU Delft, ETH Zurich, 2019. https:// repository.tudelft.nl/islandora/object/uuid\%3A4c44c1be-ac9e428d-942b-b13111c400fe?collection=education

35. Barney A, Yang W. Design freedom in eggshell 3D printed formwork, Master Thesis in MAS Architecture and Digital Fabrication, ETH Zurich, 2019.

36. Buswell RA, Silva WRLD, Jones SZ, et al. 3D printing using concrete extrusion: A roadmap for research, Cem Concr Res 2018;112:37-49.
37. Basler Hofmann. Reportage GHA future tree: Basler \& Hofmann, Basl. Hofmannde (n.d.). https://www.baslerhofmann .ch/de/aktuelles/individuelle-newseintraege/reportage-ghafuture-tree.html Accessed November 27, 2019.

38. Titan Robotics Atlas (n.d.). https://titan3drobotics.com/ atlas/ Accessed May 12, 2019.

39. CEAD Robot Extruder (n.d.). https://cead-am.com/home/ solutions/\#RobotExtruder Accessed May 12, 2019.

40. Go J, Hart AJ. Fast desktop-scale extrusion additive manufacturing. Addit Manuf 2017;18:276-284.

41. Mechtcherine V, Grafe J, Nerella VN, et al. 3D-printed steel reinforcement for digital concrete constructionManufacture, mechanical properties and bond behaviour. Constr Build Mater 2018;179:125-137.

42. Hack N, Lauer WV, Gramazio F, et al. Mesh Mould: Robotically fabricated metal meshes as concrete formwork and reinforcement. In: Proc. 11th Int. Symp. Ferrocem. 3rd ICTRC Int. Conf. Text. Reinf. Concr, 2015; pp. 347-359.

Address correspondence to:

Ena Lloret-Fritschi

Department of Architecture

Chair of Architecture and Digital Fabrication

ETH Zurich

Building HIB/Floor E/Room 37,

Stefano-Franscini-Platz 1

Zurich 8093

Switzerland

E-mail: 1loret@arch.ethz.ch 